Article

\title{
Experimental investigation of the wetting ability of microemulsion to different coal samples
}

\author{
Fengyun Sang ${ }^{2}$, Song Yan ${ }^{1 *}$, Gang Wang ${ }^{13}$, Zujie Ma ${ }^{1}$, Jinzhou Li ${ }^{1}$ \\ 1 Shandong University of Science and Technology, College of Mining and Safety Engineering, Qingdao \\ 266590, PR China \\ 2. Information-Institute, Ministry of Emergency Management of People's Republic of China, Beijing, PR \\ China \\ 3 Shandong University of Science and Technology, Mine Disaster Prevention and Control-Ministry of State \\ Key Laboratory Breeding Base, Qingdao 266590, PR China \\ * Correspondence: yansongn1@163.com
}

\begin{abstract}
To improve water injection effect, microemulsions (MEs) were used to wet coal seam compared with water and sodium dodecyl sulfate solution (SDS). Wetting effects were characterized by contact angle, X-ray diffraction, Fourier infrared spectroscopy. The results showed that the microemulsion has better spreadability on coal surface and has stronger wettability for coals of different ranks and different particle sizes than traditional wetting agents. The W/O type microemulsion is more affinity to coal than the $\mathrm{O} / \mathrm{W}$ type and the bicontinuous type.Oxygen and hydrogen contents contributed to wetting. Different wetting agents have the greatest impact on the oxygen-containing functional group absorption zone of coal, but have little impact on the change of clay mineral composition. As the content of quartz increased, the content of montmorillonite was decreased, and the hydrophilicity of coal was increased. This research proposes new ideas for solving coal dust problems and reducing coal mine disasters.
\end{abstract}

Keywords: coal wettability; microemulsion; contact angle; functional group;clay mineral;

\section{Introduction}

Coal plays a crucial part in energy structure with growing demand for the rapid growth of economy in China. Coal dust, is generated by the process of production and utilization with great number, is involved in the explosion, reduces the roadway visibility, and long-term inhalation of cold dust causes pneumoconiosis. It seriously endangers safe production of coal mine and healthy body of coal workers [1,4]. Different particle sizes of coal dust cause distinct damages to human body [5]. Small particles of coal dust can directly enter the lungs and damage the immune system, causing serious infections [6,9]. Therefore, controlling coal dust with different particle sizes has been the focus of recent research [10]. The smaller the particle size, the more difficult the wetting was [11]. The coal ranks had different polar functional groups, such as oxygen-containing functional groups, which had large differences in wettability [12]. The wettability of coal directly affects the dust suppression effect. It is of great significance to study wetting agent suitable for different coal grade and dust particle size for coal mine dust removal and disaster control [13,14].

Previously, researchers attempted to eliminate primary coal dust by water injection [15]. Since the surface tension of water was too large to spread on the surface of the hydrophobic coal seam, it was difficult to achieve the ideal wetting effect by traditional water injection [16]. Researchers further added surfactant to water, and magnetized the water, applied electric field, or used microwave radiation for dust removal $[17,18]$. Wang et al. investigated the coal-dust-wetting ability of 15 surfactants and wettability of six coal samples through contact angle experiment. The results revealed that the compound surfactant FMES and CDEA were optimal for wetting coal dust and the wettability of coal samples showed a high-low-high trend with the increase of metamorphic degree, lignite had the strongest wettability and coking coal had the weakest. Different ranks of coal required different wetting agents [19]. Yao et al. studied the wettability of three kinds of coal samples through 
the contact angle experiment, and the results demonstrated that for hydrophilic coal and hydrophobic coal with more or less oxygen-containing functional groups, appropriate dust suppressant and polymeric surfactant were used respectively to obtain better dust removal performance [20]. Chen et al. studied coal dust with different particle sizes, and the results indicated that SDBS had better wetting effect than SDS, and the smaller the particle sizes were, the worse the wettability was [21]. Ni et al. directly wetted coal dust with ionic liquid. The results demonstrated that if the content of functional groups changed, the wettability would be increased, and the contact angle would be decreased to the minimum $41.1^{\circ}$ [22]. Although previous studies have made significant progress, surfactants used in large quantities are expensive and the effect does not meet the requirements of coal mines. In order to reduce the cost and increase the efficiency of wetting different dust particles, microemulsion (MEs) was investigated for the wetting of coals with different particle sizes.

Microemulsion, a transparent or semi-transparent thermodynamically stable isotropic homogeneous liquid with ultra-low surface tension, was composed of water, oil (or other two-phase insoluble), surfactant and cosurfactant [23]. Microemulsions can dissolve hydrophobic and hydrophilic components [24], and exhibit high temperature stability in structure and phase [25], stable type for long-term storage [26], and coexistence of hydrophilic and lipophilic substances [27]. It has good water solubility and oil solubility $[28,29]$, which allows coal seam wetting. The effect of microemulsion on the hydrophilicity of glass surface was characterized by mass spectrometry (MS) and contact angle measurement. The results show that the microemulsion can change the hydrophilic and hydrophobic properties of glass surface [30]. The interaction of diluted microemulsion with shale and sand was studied by Andrei S. Zelenev. The results showed that compared with o/w and w/o microemulsion, the diluted equilibrium microemulsion had the largest contact angle and the worst wettability [31]. Microemulsions can change the wettability of solids [32] and dense sandstone [33]. Microemulsion can change the wettability of solid surface and the wettability of microemulsion is stronger than that of surfactant [34,35]. Moreover, it can generate ultra-low surface tension through the enhancement of oil [36], and increase the mobility of non-polar molecules [37]. The wettability of bicontinuous microemulsions was studied by Vaijayanti A. Tamhane [38], and the results showed that the microemulsions have good solubility, low interfacial tension, and controllable water content. It can form a smaller contact angle on hydrophobic leaves [38], has better spreading capability and good wetting effect [39]. As microemulsions have these excellent properties, it is of great significance to study the wettability of microemulsions to coal to solve coal dust problems and prevent natural disasters in coal mines.

In this report, the wetting performance of microemulsion on coal was studied and compared with traditional wetting agents. The contact angle experiments were used to directly characterize the comparative wetting results. We also quantitatively characterized the functional groups, clay minerals of Yuquan lean coal treated with different wetting agents using Fourier transform infrared spectroscopy, X-ray diffraction experiments, and fitting parameters to the contact angle to obtain the relationship between parameter changes and wettability. This study will provide a theoretical basis for the selection of efficient wetting agents in coal mines.

\section{Theory and experiment}

Contact angle, based on Young equation, is the most direct index of wettability of reactive materials with the wetting process, which is related to the interfacial free energy of the solid-gas, solid-liquid, and liquid-gas. When a droplet is placed on a solid surface, the droplet can spread out on the solid surface automatically, and the droplet exists at a certain contact angle with the solid surface [19].

$$
\gamma_{S G}-\gamma_{S L}=\gamma_{L G} \cdot \cos \theta
$$

Where, $\gamma S G, \gamma L G$ and $\gamma S L$ are the solid-gas, liquid-gas, solid-liquid interfacial tensions $(\mathrm{N} / \mathrm{m})$, respectively, and $\theta\left(0-180^{\circ}\right)$ is the contact angle at the solution interface [40]. $0^{\circ}$ indicates that the solution is completely wet, when the spread on coal surface is complete. $180^{\circ}$ indicates that the 
solution shows no spreading or wetting. Therefore, the spreading of the solution was used to describe the wetting of coal dust.

\section{Experimental materials and equipment}

\subsection{Coal samples and wetting agents}

Sodium dodecyl sulfate (SDS), an anionic surfactant, with distilled water as the contrast agent was purchased from Tianjin Dingshengxin chemical co, LTD. Kerosene, $98 \%$ ethanol were purchased from the Chengdu aikeda chemical reagent co. LTD.

The distilled water and ethanol, $1 \mathrm{wt} \%$ SDS solution, kerosene mixed with certain proportion, and materials spontaneously formed homogeneous microemulsion. According to the water-oil ratio of 2:1, 1:2 and 1:1, the microemulsion was synthesized in batches to produce $\mathrm{O} / \mathrm{W}, \mathrm{W} / \mathrm{O}$, and bicontinuous (B) type. The four - phase composition of microemulsion was spontaneously combined at room temperature $\left(19{ }^{\circ} \mathrm{C}\right)$ in autumn in Qingdao, Shandong province, China.

The typical coal samples used in the experiment were Sihe anthracite, Cuijiagou soft coal, Yuquan lean coal, Wanglou 1/3 coking coal, Tangkou gas coal. From anthracite coal with the highest metamorphic degree to gas coal with medium or low metamorphic degree, the five kinds of coal samples are the representatives for the entire difficult wetting coal system. The proximate analyses and ultimate analysis of coal samples are shown in Table. 1.

The hydrophilic and hydrophobic properties of the four-phase substance were simplified into molecular monomers according to the wetting substance, and amphiphilic molecules were simplified into molecular monomers with a hydrophilic head and a hydrophobic or lipophilic tail. The synthesized microemulsion existed in the form of tiny droplets were simplified into threedimensional small molecular groups (Fig.1).

Table 1. The proximate analyses andultimate analysis of coal samples

\begin{tabular}{|c|c|c|c|c|c|c|c|c|c|}
\hline \multirow[t]{2}{*}{ Sample } & \multicolumn{4}{|c|}{ Proximate analysis (wt \%) } & \multicolumn{5}{|c|}{ Ultimate analysis (wt \%) } \\
\hline & $\mathbf{M}_{\text {ad }}$ & $\mathrm{A}_{\mathrm{ad}}$ & $\mathrm{V}_{\mathrm{ad}}$ & $F_{\text {cad }}$ & $\mathrm{C}_{\text {adf }}$ & $H_{\text {daf }}$ & $\mathbf{O}_{\text {daf }}$ & $\mathbf{N}_{\text {daf }}$ & $\mathrm{S}_{\mathrm{t}, \mathrm{d}}$ \\
\hline anthracite & 0.93 & 14.98 & 9.58 & 74.51 & 93.01 & 2.98 & 2.23 & 1.1 & 0.32 \\
\hline soft coal & 3.52 & 15.58 & 36.54 & 44.36 & 81.99 & 4.45 & 11.29 & 0.71 & 1.19 \\
\hline lean coal & 1.05 & 15.47 & 18.93 & 64.55 & 90.24 & 4.13 & 3.1 & 1.03 & 1.29 \\
\hline $1 / 3$ coking coal & 1.1 & 15.27 & 34.22 & 49.41 & 86.58 & 5.03 & 5.3 & 1.17 & 1.71 \\
\hline gas coal & 3.43 & 16.3 & 39.27 & 41 & 82.04 & 4.78 & 10.87 & 1.19 & 0.86 \\
\hline
\end{tabular}

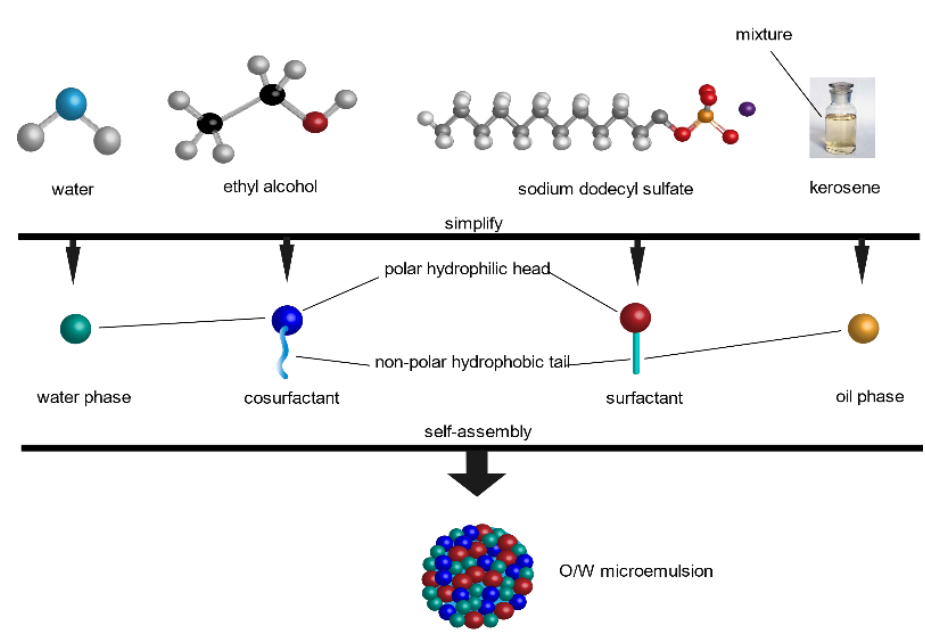

Fig.1. Self-assembly of microemulsion 


\subsection{Experimental facilities}

The raw coal was crushed and sieved into powders with 20 mesh, 120 mesh, and 325 mesh. Powders of $0.6 \mathrm{~g}$ was compacted with compressing pressure at $20 \mathrm{MPa}$ for $2 \mathrm{~min}$ for contact angles test using the YP-24 type tablet press machine manufactured by Josvok Technology Co.,Ltd (Fig.2). During the process of coal pulverization, the surface structure became more complex and the wettability was changed [41]

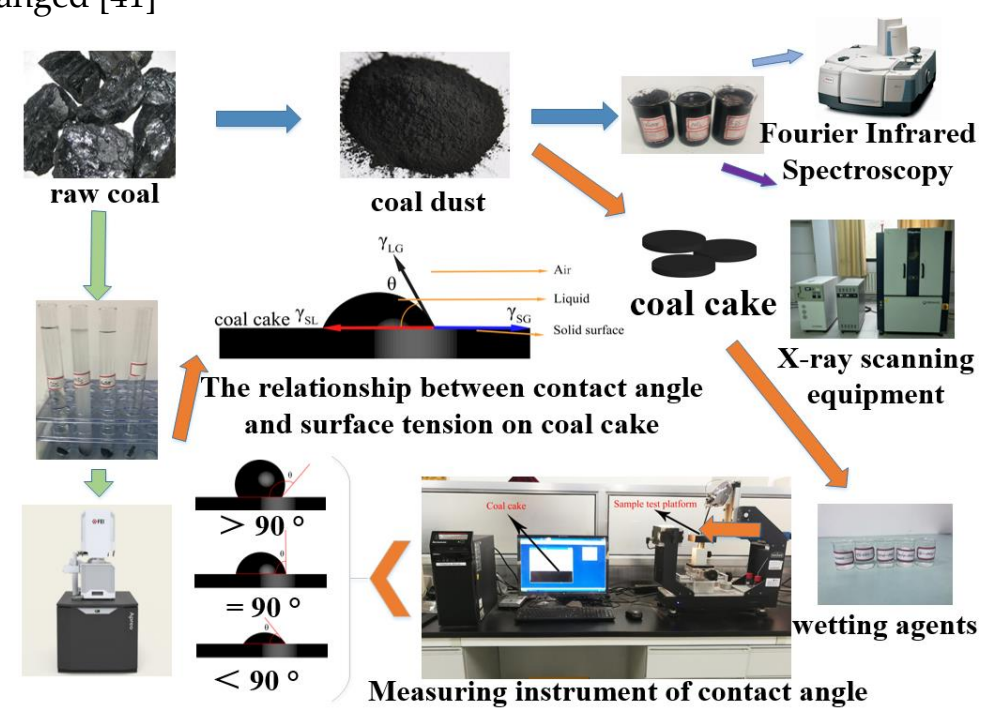

Fig.2. Coal cake making and wetting angle measurement

\subsection{Indirect characterization of wettability}

To study the changes of physical and chemical properties of coal samples after wetting agent treatment, lean coal was to be selected for experiments. The mixed sample (the mass ratio of coal sample to $\mathrm{KBr}$ is 1:1000) is ground evenly and put into the mold. Then place the mold on the tablet press and press for 2 min with a pressure of $15 \mathrm{MPa}$. Finally the test is carried out with a Nicolet iS50 FT-IR Fourier infrared spectrometer made in the United States. The pulverized coal soaked in wetting agent for 5 days was put into the drying oven for 24 hours $\left(20^{\circ} \mathrm{C}\right)$. After taking out, the sample was placed on the slide and scanned with a Rigaku Utima IV X-ray diffractometer made in Japan by Rigaku corporation. A large chunk of coal is crushed, and small coal pieces at the same position in the same coal are selected to ensure that the properties of the coal pieces are similar. Then four small coal blocks with similar surface morphology are selected by coal surface scanning to ensure that the coal surface treated with the reagents can form a more scientific control group. Then they are dried by a drying oven at $20^{\circ} \mathrm{C}$ for $24 \mathrm{~h}$ to obtain the coal sample to be tested. Finally, the coal sample is scanned with an APREO scanning electron microscope made in the United States (Fig.2).

\section{Results and discussion}

\subsection{Contact angle of different coal samples}

The contact angle directly reflected the wettability of the wetting agent. 


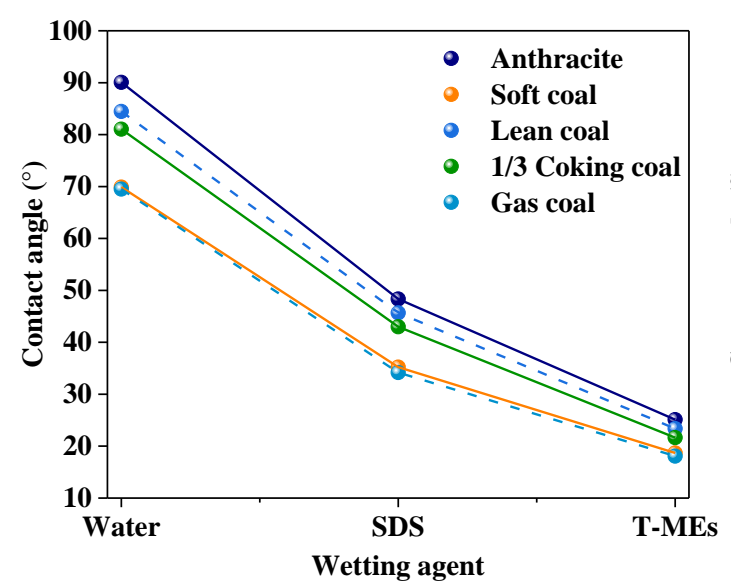

(a)

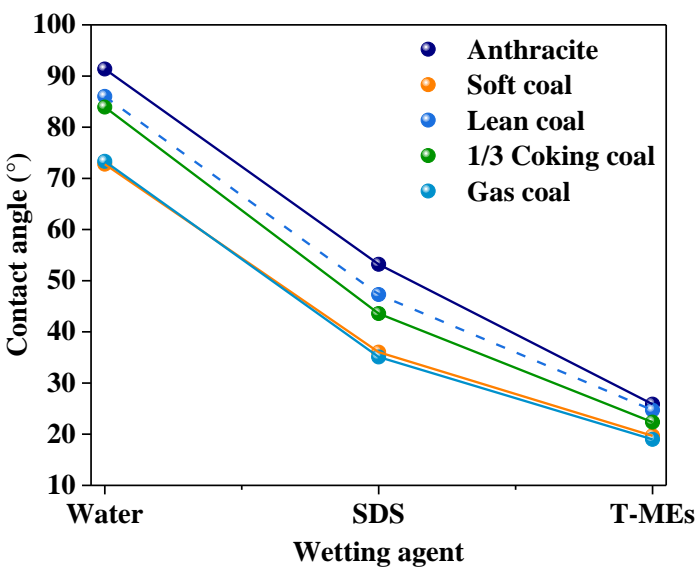

(b)

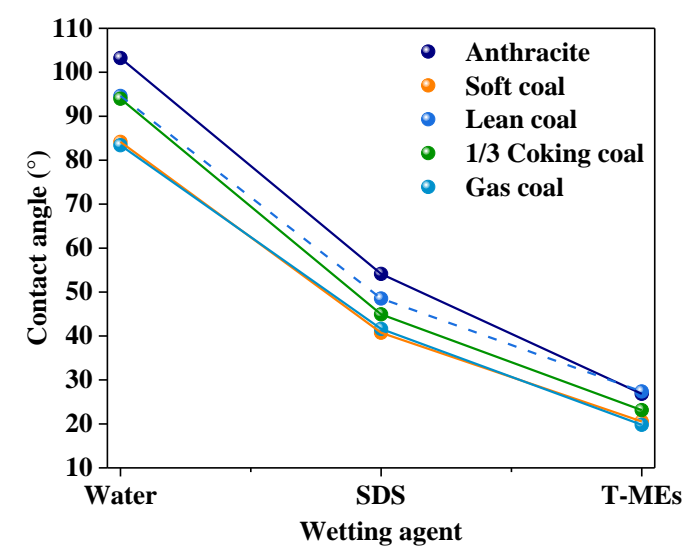

(c)

Fig. 3 Contact angle of traditional wetting agent and microemulsion to coal

Fig. 3 is a comparison diagram of the contact angle of traditional wetting agent and the average contact angle of three-phase microemulsion, where (a), (b), (c) the coal cake particle size is 20 mesh, 120 mesh, and 325 mesh. It can be seen from the figure that different contact angles of wetting agents vary greatly, with watercoal contact angle being the largest, followed by SDS-coal, and microemulsion-coal contact angle being the smallest, indicating that water has the worst wettability, followed by SDS. Microemulsion has the best wettability. The microemulsion droplets reach the nanometer scale, and the water and oil phases are connected by surfactants and co-surfactants, which have better spreadability, so they can spread smoothly on the surface of the hydrophobic coal seam to form a coal surface coating layer and change the wetting of coal Sex. Reduce the dust production of primary coal dust, and finally achieve the goal of pre-injecting microemulsion to prevent various natural disasters.

It can be seen from the figure that the contact angles of different coal ranks are obviously different, from largest to smallest, they are anthracite, lean coal, 1/3 coking coal, bituminous coal and gas coal, indicating that anthracite has the strongest surface hydrophobicity. It is difficult for the wetting agent to spread on the coal surface, and the dustproof task is the most difficult. Compared with traditional wetting agents, the microemulsion has the smallest contact angle, the best wettability, and the strongest spreadability on the anthracite surface, indicating that the microemulsion can more easily wrap the anthracite. Lean coal and $1 / 3$ coking coal have similar laws. Bituminous coal and gas coal have similar contact angles, indicating that bituminous coal and gas coal have similar wettability. Among the tested coal ranks, wetting agents have the strongest wettability on bituminous coal and gas coal and have the best effect.

The different contact angles of different particle sizes indicate that the wettability of different particle sizes is different, and the wettability of the same coal rank shows differences. It can be seen from Figure 1 that the contact angle of the briquettes with a particle size of 20 mesh and 120 mesh is relatively small, but when the briquettes have a particle size of 325 mesh, the contact angle increases greatly and the wettability becomes 
worse. Smaller, the physical and chemical properties of the surface of the coal powder become more complex, and the lower the affinity for the wetting agent, the more difficult for the wetting agent to spread on the surface of the coal cake to wrap the coal seam. It can be seen from (c) that when the particle size is 325 mesh, the difference in contact angle formed by the wetting agent on the surface of coal cakes of different coal ranks decreases, indicating that the surface wettability of coals of different coal ranks is more similar as the particle size decreases. The microemulsion-coal contact angle increases as the particle size decreases, but the overall wettability is good.

In short, although the increase in coal rank and the decrease in coal particle size will enhance the hydrophobicity of the coal surface, the microemulsion has stronger wettability than traditional wetting agents and is easier to spread and wrap the coal seam on the coal surface.

\subsection{Wettability of three phase microemulsion}

At the average ceramic temperature of $968.3^{\circ} \mathrm{C}$ and the vacuum of approximately $30 \mathrm{kPa}$, the air was quickly pumped in, and the pressure of gas oxidation was measured in real-time. The picture shows the real-time pressure detection chart.

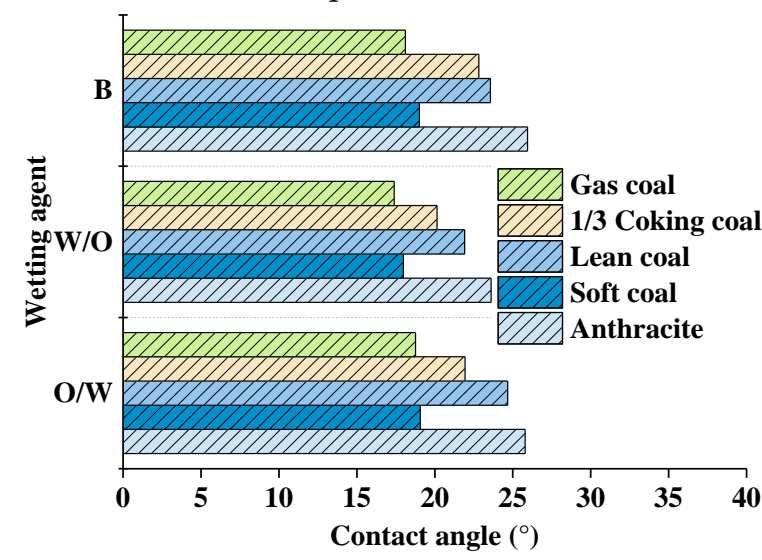

(a)

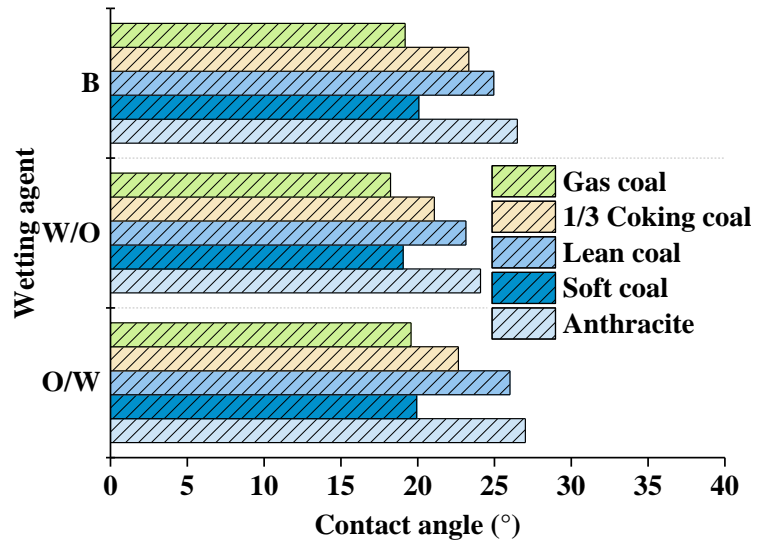

(b)

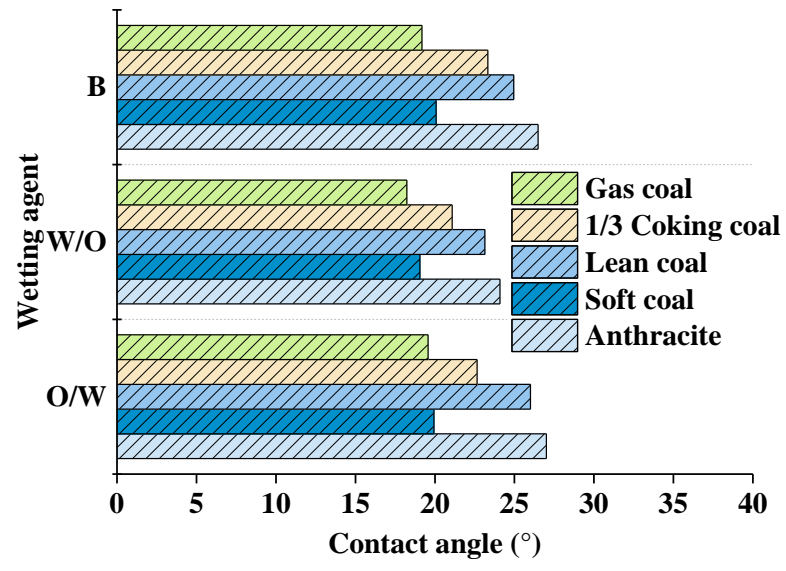

(c)

Fig.4 Contact angle of three-phase microemulsion with coal

Fig. 4 is the contact angle formed by the three-phase microemulsion on the surface of the coal cake, where (a), (b), (c) the particle size of the coal cake is 20 mesh, 120 mesh, and 325 mesh. It can be seen from the figure that the contact angle of the three-phase microemulsion to the same coal rank and the same particle size is not much different, indicating that the wettability of the three-phase microemulsion to coal is at the same level. Among the three-phase microemulsions, the contact angle of W/O-coal is the smallest, the contact angles of the double continuous type and the O/W type are similar, and the double continuous type is slightly better, indicating that the $\mathrm{W} / \mathrm{O}$ type microemulsion has better wettability than the double continuous type and $\mathrm{O} / \mathrm{W}$ type. The $\mathrm{W} / \mathrm{O}$ type is composed of the oil phase wrapping the water phase core to form nano-droplets, and the oil and water are 
connected by the active agent to form a microemulsion wetting agent with wetting properties. The hydrophobicity of the coal surface makes it difficult for the droplets to spread, but it is compatible with oil. W/O type microemulsions have an oil-phase shell, so it is easier to affinity with the hydrophobic coal surface. The microemulsion with stronger affinity with the coal surface is easier to spread on the coal surface, forming a smaller contact angle and achieving better wetting effect. The bicontinuous microemulsion has the same water-oil ratio, and when the coal seam is spread, the lipophilic side preferentially forms a smaller contact angle with coal. $\mathrm{O} / \mathrm{W}$ type microemulsion oil phase core is wrapped by water phase, which is more difficult than W/O type when the coal seam is wetted. However, because the three-phase microemulsion has a smaller water-oil ratio, the contact angle does not change much.

In a word, the wettability of three-phase microemulsion to coal is different, but the difference is not big. W/O type microemulsion has stronger affinity to hydrophobic coal surface than $\mathrm{O} / \mathrm{W}$ type and bicontinuous type.

\subsection{Fitting relationship between contact angle and proximate composition and ultimate composition}

Proximate composition and ultimate composition are the most recent parameters of coal. The change trend of contact angle must affect the changes of coal parameters and must be affected by it. Therefore, exploring the relationship between contact angle and industrial analysis and elemental analysis is helpful for in-depth discussion of coal The nature of wet changes.
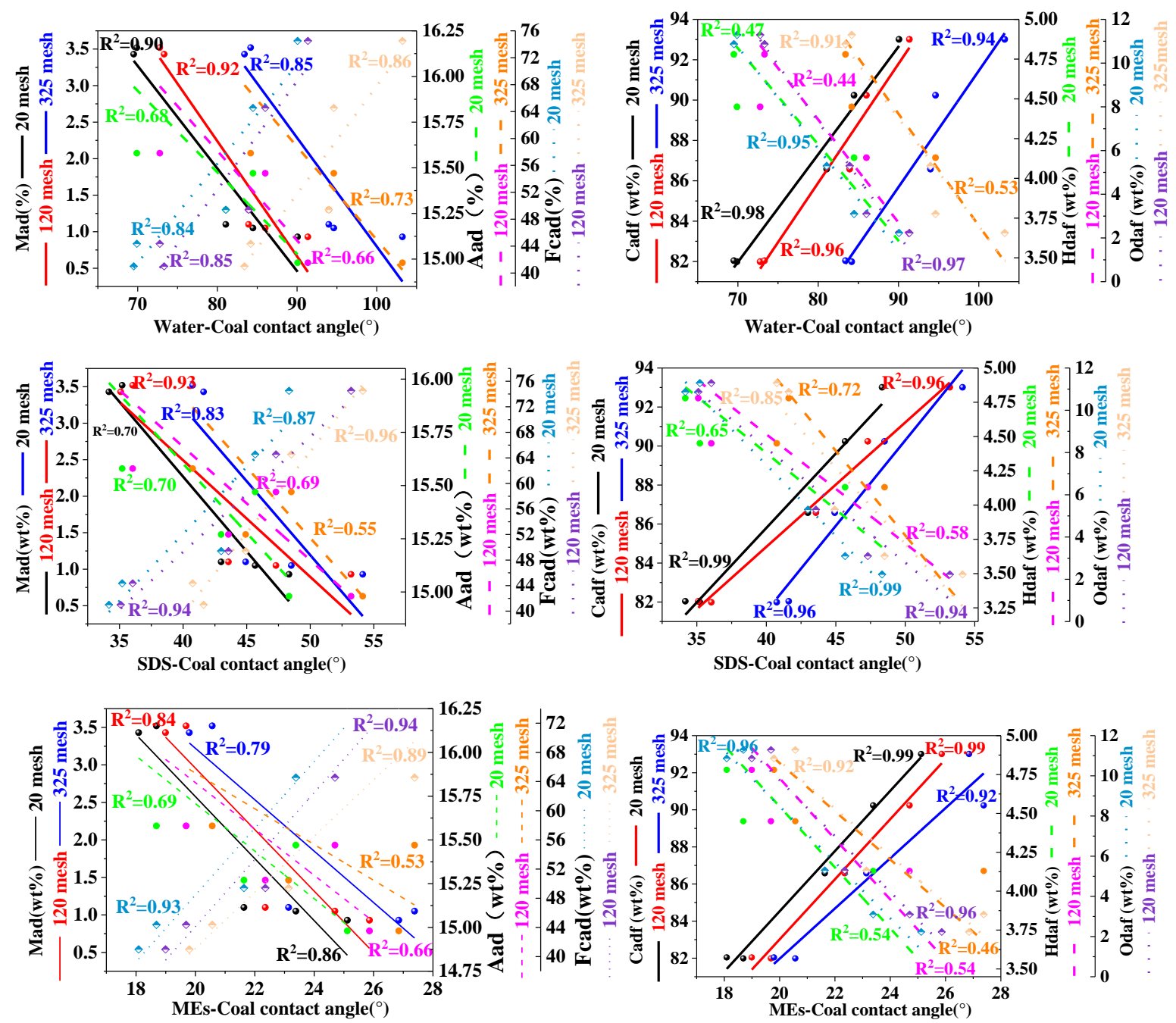

Fig.5. Relationship between contact angles of different wetting agents and proximate composition and ultimate 
Fig.5 illustrates the proximate composition and ultimate composition straight lines of water-coal contact angle, SDS-coal contact angle, three-phase MEs-coal average contact angle, and five grades of coal. Proximate composition and ultimate composition in coal samples were greatly affected by the coal rank. Coal samples treated with different wetting agents had the same correlation with the fit curves of proximate composition and ultimate composition. The contact angle was positively correlated with the fixed carbon and carbon elements in the coal, indicating that the larger the fixed carbon and carbon element contents, the worse the wettability. The higher the content of fixed carbon and carbon elements, the higher the degree of deterioration of coal, resulting in poor wettability, which was consistent with the results of contact angle experiments. The contact angle was decreased with the increase of moisture and ash in the coal, indicating that the moisture and ash were positively related to the wettability of the coal. The contact angle was decreased with increasing hydrogen and oxygen content. We found that the content of hydrogen and oxygen contributed to the wetting of coal. In the process of coal deterioration, as the coal rank rises, the oxygen-containing functional groups fall off, which reduces the affinity of coal for water and directly determines the wettability of coal. MEs did not change the proximate composition and ultimate composition of raw coal, and the contact angle was affected by the proximate composition and ultimate composition similarly as traditional wetting agents.

\subsection{Experiment of Fourier Infrared Spectroscopy}

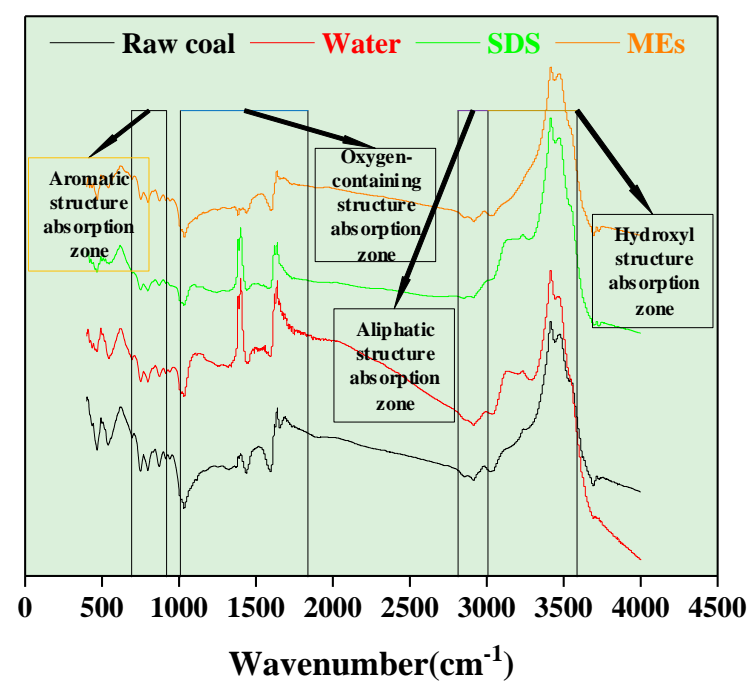

Fig.6. Fourier infrared spectra of different coal samples

Fig.6 is the Fourier infrared spectrum of coal samples treated with different wetting agents.The four samples had similar spectral curves, and the wetting agent did not change the type of functional groups in the samples but the ratio of functional groups. The spectrum is divided into four parts, namely aromatic structure absorption zone, oxygen-containing structure absorption zone, aliphatic structure absorption zone and hydroxyl structure absorption zone. The oxygen-containing structure absorption zone spectrum of the four coal samples changed greatly, and the other three absorption zones did not change much, indicating that the wetting agent mainly affects the coal's own structure through oxygen-containing functional groups, and ultimately determines the hydrophilic and hydrophobic properties of the coal. It can be seen from Figure 5 that the increase of oxygen and hydrogen is helpful for wetting, so the wetting agent's wettability to coal is enhanced mainly by adding oxygen and hydrogen to form oxygen-containing functional groups, and finally oxygen The functional group area percentage changes. Wettability was affected as the ratio of functional groups was changed. 
$4.5 X$ - ray diffraction experiment

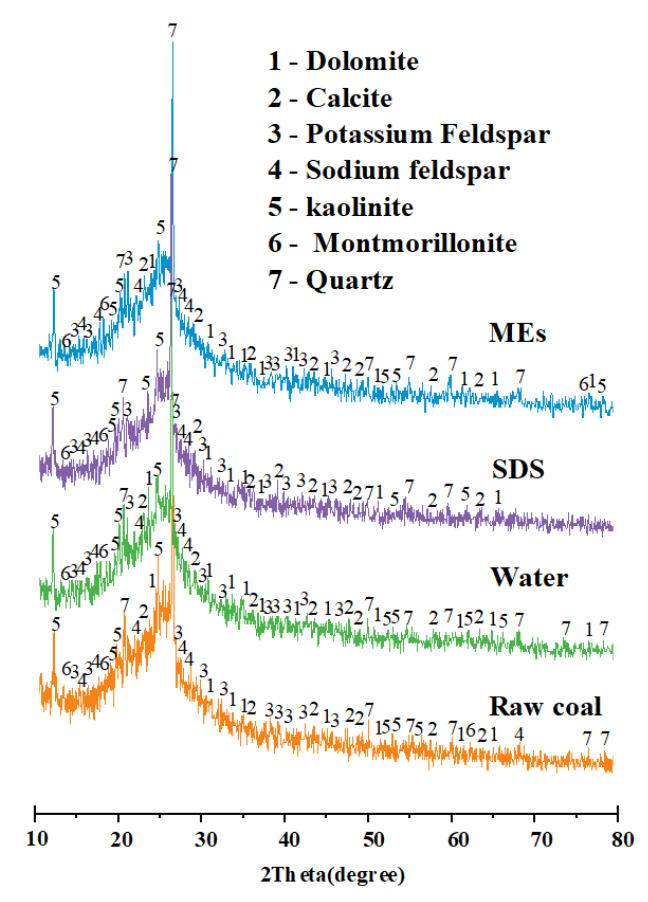

Fig.7. X-ray diffraction spectra of four coal samples

Fig.7 is an X-ray diffraction comparison chart of coal sample and raw coal treated by wetting agent. It can be seen from the figure that the types of clay minerals of the coal samples did not change after being treated with different wetting agents, indicating that the three wetting agents did not completely dissolve the clay minerals and did not produce a large corrosive effect on the clay minerals, but only slightly changed The relative content of clay minerals.

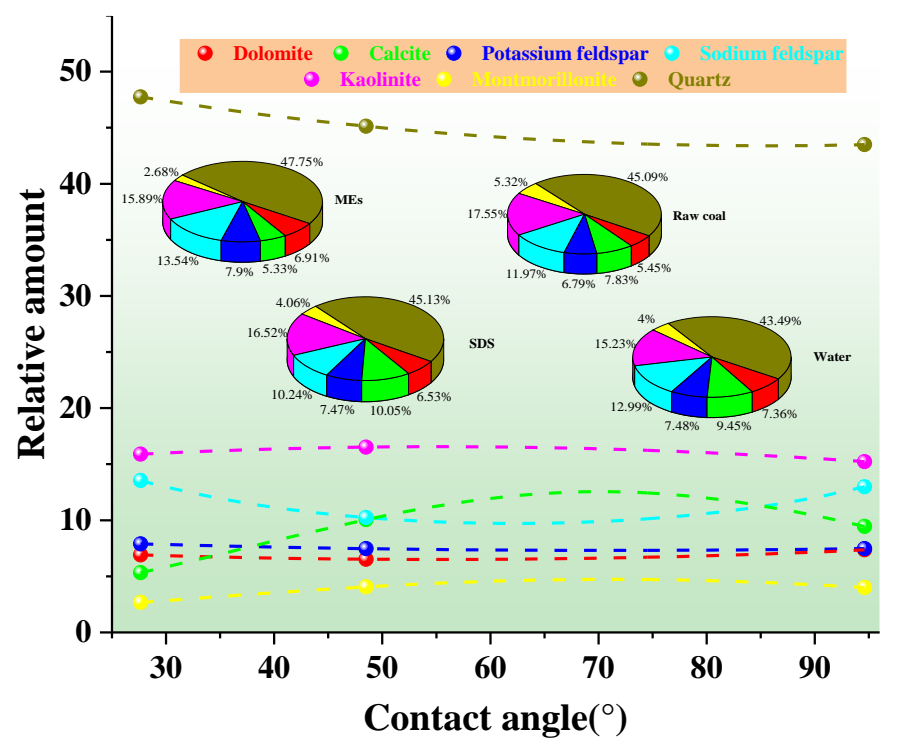

Fig.8. Relationship between clay mineral content and coal wettability

As can be seen from Fig.8,the proportion of each clay mineral in coal samples was mostly the same. The content of quartz was the largest, and the proportion reached about $50 \%$ of the total clay minerals of each coal sample. The content of montmorillonite was the smallest, only $2.68 \%-5.32 \%$. We discovered that the fitting curve of the relative content of quartz and the contact angle were well correlated, indicating that quartz had a strong effect on wettability. The smaller the relative content 
of quartz is, the larger the contact angle is, and the worse the wettability is. The MEs treated coal sample had the largest quartz content, with a relative content of $47.75 \%$, which increased the wetting effect of MEs on coal. The relative content of dolomite, potassium feldspar, and kaolinite was slightly affected by the contact angle, indicating that the change in wettability of the coal sample after MEs treatment was independent of the relative content of dolomite, potassium feldspar, and kaolinite. The influence of calcite and albite on coal wettability can be divided into two stages, the first stage is $27^{\circ}$ to $70^{\circ}$, the second stage is $70^{\circ}$ to $95^{\circ}$, and the first stage accounts for a larger proportion. The albite decreases in the first stage and increases in the second stage, indicating that the increase in the percentage of albite promotes wetting in the first stage and inhibits wetting in the second stage. Calcite is the opposite of albite. The first stage is to inhibit wetting, and the second stage is to promote wetting. The relative content of montmorillonite is positively correlated with the contact angle, the contact angle increases with the relative content, and the wettability becomes worse. The content of montmorillonite in the coal samples is relatively small, and the changes after being treated by wetting agent are subtle. From the fitting situation, although montmorillonite has hydrophilicity and absorptivity, it does not have a big impact on the wettability of coal. However, the expansion coefficient of montmorillonite varies from several times to more than 30 times after absorbing water, blocking the pores of coal, and small changes in volume may also seriously reduce the wetted area of coal. On the whole, the slight change of montmorillonite will not enhance the wettability of coal after being treated by wetting agent.

\section{Conclusion}

In this paper, we studied the wettability of MEs on coals of different coal ranks and different particle sizes and compared them with traditional water-injection wetting agents. Yuquan lean coal was selected to measure the functional groups of coal, clay minerals and coal surface cracks after being treated with different wetting agents. The conclusions are as follows:

1. Under the same coal rank and the same wetting agent, the higher the coal rank is, the worse the wettability is. Under the same coal rank and the same wetting agent, the smaller the particle size is, the worse the wettability is. Under the same coal rank and the same particle size, the MEs-coal contact angle was the smallest. Among the tested coal samples, the water-anthracite-325mesh contact angle was the largest at $103.23^{\circ}$, and the W/O MEs-gas coal-20 mesh contact angle was the smallest at $17.39^{\circ}$. The microemulsion exhibited good wettability to coal.

2. The contact angle of the three-phase microemulsion to coal, the minimum contact angle obtained at W/O MEs-gas coal-20 mesh was $17.39^{\circ}$, and the maximum value at $\mathrm{O} / \mathrm{W}$ MEs-anthracite325 mesh was $27.91^{\circ}$. W/O type microemulsion demonstrated superior wetting effect than O/W type and bicontinuous type.

3. The moisture and ash of coal were positively correlated with the wettability of coal, and hydrogen and oxygen contributed to the wetting of coal.

4, The wettability of the wetting agent to the coal is enhanced mainly by changing the area percentage of oxygen-containing functional groups.

5. The fitting curve of the relative content of quartz and the contact angle has a good correlation. The smaller the relative content of quartz, the larger the contact angle and the worse the wettability. The influence of calcite and sodium feldspar on wettability presents stage change. Montmorillonite absorbs and expands and blocks coal pores to reduce the wetting area, and its own hydrophilicity does not enhance the wettability of coal.

In this paper, we reported for the first time that microemulsions displayed good wettability to coal, which was of great significance for solving coal mine disasters, wrapping primary dust to reduce roadway pollution, and alleviating the harm of coal dust to workers' health. In addition, it will provide theoretical basis for the future development of degradable microemulsion wetting agents.

Acknowledgments: The authors thank the support of the National Natural Science Foundation of China (Project No. 51934004; 51674158; 51574158; 51474106), Major Program of Shandong Province Natural Science Foundation (ZR2018ZA0602) the Taishan Scholar Talent Team Support 
Plan for Advantaged \& Unique Discipline Areas, Shandong province colleges and universities qingchuang science and technology support plan(2019KJH006).

Conflicts of Interest: The authors declare no conflict of interest.

\section{References:}

1. Gianoncelli, A., Rizzardi, C., Salomon, D., Canzonieri, V. \& Pascolo, L. Nano-imaging of environmental dust in human lung tissue by soft and hard X-ray fluorescence microscopy. Spectrochimica Acta Part B: Atomic Spectroscopy 147(2018)71-78.

2. Man, C. K. \& Harris, M. L. Participation of large particles in coal dust explosions. Journal of Loss Prevention in the Process Industries 27(2014) 49-54, doi:10.1016/j.jlp.2013.11.004.

3. Qian, Q. Z. et al. Relationship of cumulative dust exposure dose and cumulative abnormal rate of pulmonary function in coal mixture workers. The Kaohsiung journal of medical sciences 32(2016)4449, doi:10.1016/j.kjms.2015.11.003.

4. Cai, P., Nie, W., Chen, D., Yang, S. \& Liu, Z. Effect of air flowrate on pollutant dispersion pattern of coal dust particles at fully mechanized mining face based on numerical simulation. Fuel 239(2019)623635, doi:10.1016/j.fuel.2018.11.030.

5. Park, M. et al. Differential toxicities of fine particulate matters from various sources. Scientific reports8(2018)17007, doi:10.1038/s41598-018-35398-0.

6. Leon-Mejia, G. et al. Intratracheal instillation of coal and coal fly ash particles in mice induces DNA damage and translocation of metals to extrapulmonary tissues. Sci. Total Environ. 625(2018)589-599, doi:10.1016/j.scitotenv.2017.12.283.

7. Moreno, T. et al. Trace element fractionation between PM10 and PM2.5 in coal mine dust: Implications for occupational respiratory health. International Journal of Coal Geology203(2019)52-59, doi:10.1016/j.coal.2019.01.006.

8. Caballero-Gallardo, K. \& Olivero-Verbel, J. Mice housed on coal dust-contaminated sand: A model to evaluate the impacts of coal mining on health. Toxicol. Appl. Pharmacol.294(2016)11-20, doi:10.1016/j.taap.2016.01.009.

9. Lam, C. W., James, J. T., McCluskey, R. \& Hunter, R. L. Pulmonary toxicity of single-wall carbon nanotubes in mice 7 and 90 days after intratracheal instillation. Toxicol. Sci.77(2004)126-134, doi:10.1093/toxsci/kfg243.

10. Han, L. et al, 2017. Survival Analysis of Coal Workers' Pneumoconiosis (CWP) Patients in a StateOwned Mine in the East of China from 1963 to 2014. International journal of environmental research and public health 14, doi:10.3390/ijerph14050489.

11. Chen, Y. et al. Characterization of coal particles wettability in surfactant solution by using four laboratory static tests. Colloids and Surfaces A: Physicochemical and Engineering Aspects567(2019)304-312, doi:10.1016/j.colsurfa.2019.01.068.

12. Guanhua, N., Zhao, L., Qian, S., Shang, L. \& Kai, D. Effects of [Bmim][Cl] ionic liquid with different concentrations on the functional groups and wettability of coal. Adv. Powder Technol.30(2019)610624, doi:10.1016/j.apt.2018.12.008.

13. Zhou, G. et al. The development and characterization of a novel coagulant for dust suppression in open-cast coal mines. Adsorption Science \& Technology 36(2017) 608-624, doi:10.1177/0263617417711025.

14. Zhang, H. et al. Preparation and experimental dust suppression performance characterization of a novel guar gum-modification-based environmentally-friendly degradable dust suppressant. Powder Technol. 339(2018) 314-325, doi:10.1016/j.powtec.2018.08.011.

15. Cheng, W., Liu, Z., Yang, H. \& Wang, W. Non-linear seepage characteristics and influential factors of water injection in gassy seams. Exp. Therm Fluid Sci. 91(2018)41-53, doi:10.1016/j.expthermflusci.2017.10.002.

16. Hetang Wanga, , Lin Zhang. Experimental investigation on the wettability of respirable coal dust based on infrared spectroscopy and contact angle analysis. Advanced Powder Technology.28(2017)3130-3139 doi:10.1016/j.apt.2017.09.018. 
17. Zhou, Q., Qin, B., Wang, J., Wang, H. \& Wang, F. Effects of preparation parameters on the wetting features of surfactant-magnetized water for dust control in Luwa mine, China. Powder Technol. 326(2018)7-15, doi:10.1016/j.powtec.2017.12.002.

18. Asada, M., Kanazawa, Y., Asakuma, Y., Honda, I. \& Phan, C. Surface tension and oscillation of water droplet under microwave radiation. Chem. Eng. Res. Des. 101(2015) 107-112, doi:10.1016/j.cherd.2015.05.019.

19. Wang, X., Yuan, S., Li, X. \& Jiang, B. Synergistic effect of surfactant compounding on improving dust suppression in a coal mine in Erdos, China. Powder Technol. 344(2019)561-569, doi:10.1016/j.powtec.2018.12.061.

20. Yao $Q, \mathrm{Xu}$ C, Zhang $\mathrm{Y}$, et al. Micromechanism of coal dust wettability and its effect on the selection and development of dust suppressants[J]. Process Safety and Environmental Protection, 2017, 111:726732.

21. Chen, Y. et al. Characterization of coal particles wettability in surfactant solution by using four laboratory static tests. Colloids and Surfaces A: Physicochemical and Engineering Aspects 567, 304312, doi:10.1016/j.colsurfa.2019.01.068 (2019)

22. Guanhua, N., Zhao, L., Qian, S., Shang, L. \& Kai, D. Effects of [Bmim][Cl] ionic liquid with different concentrations on the functional groups and wettability of coal. Advanced Powder Technology 30, 610-624, doi:10.1016/j.apt.2018.12.008 (2019).

23. Prevost, S., Gradzielski, M. \& Zemb, T. Self-assembly, phase behaviour and structural behaviour as observed by scattering for classical and non-classical microemulsions. Advances in colloid and interface science 247(2017) 374-396, doi:10.1016/j.cis.2017.07.022.

24. Carrillo, C. A., Saloni, D., Lucia, L. A., Hubbe, M. A. \& Rojas, O. J. Capillary flooding of wood with microemulsions from Winsor I systems. Journal of colloid and interface science 381, 171-179, doi:10.1016/j.jcis.2012.05.032 (2012).

25. Schulreich, C. et al. Bicontinuous microemulsions with extremely high temperature stability based on skin friendly oil and sugar surfactant. Colloids and Surfaces A: Physicochemical and Engineering Aspects 418, 39-46, doi:10.1016/j.colsurfa.2012.10.039 (2013).

26. $\mathrm{Li}, \mathrm{G}$. et al. In vitro and in vivo evaluation of a simple microemulsion formulation for propofol. International journal of pharmaceutics 425, 53-61, doi:10.1016/j.ijpharm.2012.01.011 (2012).

27. [Kunitake, M., Kuraya, E., Kato, D., Niwa, O. \& Nishimi, T. Electrochemistry in bicontinuous microemulsions based on control of dynamic solution structures on electrode surfaces. Current Opinion in Colloid \& Interface Science 25, 13-26, doi:10.1016/j.cocis.2016.05.004 (2016).

28. $\mathrm{Xu}, \mathrm{Y}$. et al. Reverse microemulsion synthesis of layered gadolinium hydroxide nanoparticles. Journal of Solid State Chemistry 258, 320-327, doi:10.1016/j.jssc.2017.10.031 (2018).

29. Achinta Bera. et al. Water solubilization capacity, interfacial compositions and thermodynamic

30. Achinta Bera, Keka Ojha, T. Kumar, Ajay Mandal,Water solubilization capacity, interfacial compositions and thermodynamic parameters of anionic and cationic microemulsions, Colloids and Surfaces A: Physicochemical and Engineering Aspects, Volume 404,2012,Pages 70-77.

31. Nagy, A., Kennedy, J. P., Wang, P., Wesdemiotis, C. \& Hanton, S. D. Extent of coverage of surfaces treated with hydrophobizing microemulsions: A mass spectrometry and contact angle study. Applied Surface Science 252, 3751-3759, doi:10.1016/j.apsusc.2005.05.063 (2006).

32. Zelenev, A. S., Champagne, L. M. \& Hamilton, M. Investigation of interactions of diluted microemulsions with shale rock and sand by adsorption and wettability measurements. Colloids and Surfaces A: Physicochemical and Engineering Aspects 391, 201-207, doi:10.1016/j.colsurfa.2011.07.007 (2011).

33. Qin, Tianzhu, Javanbakht, Gina, Goual, Lamia, Piri, Mohammad, \& Towler, Brian. . Microemulsionenhanced displacement of oil in porous media containing carbonate cements. Colloids \& Surfaces A Physicochemical \& Engineering Aspects, 530, 60-71.

34. Dong, B. et al. Formation damage prevention using microemulsion in tight sandstone gas reservoir. Journal of Petroleum Science and Engineering 173, 101-111, doi:10.1016/j.petrol.2018.10.003 (2019).

35. Javanbakht, G., Arshadi, M., Qin, T. \& Goual, L. Micro-scale displacement of NAPL by surfactant and microemulsion in heterogeneous porous media. Advances in Water Resources 105, 173-187, doi:10.1016/j.advwatres.2017.05.006 (2017).

36. Kumar, A., Kumar Saw, R., \& Mandal, A. RSM optimization of oil-in-water microemulsion stabilized by synthesized zwitterionic surfactant and its properties evaluation for application in enhanced oil 
recovery. Chemical Engineering Research and Design 147, 399-411, https://doi.org/10.1016/j.cherd.2019.05.034 (2019).

37. Pal, N., Kumar, S., Bera, A. \& Mandal, A. Phase behaviour and characterization of microemulsion stabilized by a novel synthesized surfactant: Implications for enhanced oil recovery. Fuel 235, 9951009, doi:10.1016/j.fuel.2018.08.100 (2019).

38. Lowry, E., Sedghi, M. \& Goual, L. Molecular simulations of NAPL removal from mineral surfaces using microemulsions and surfactants. Colloids and Surfaces A: Physicochemical and Engineering Aspects 506, 485-494, doi:10.1016/j.colsurfa.2016.07.002 (2016). [35] Li, Q., Lin, B., Zhao, S. \& Dai, H. Surface physical properties and its effects on the wetting behaviors of respirable coal mine dust. Powder Technol. 233(2013)137-145, doi:10.1016/j.powtec.2012.08.023.

39. Tamhane, V. A. , Dhaware, D. G. , Khandelwal, N. , Giri, A. P. , \& Panchagnula, V. . (2012). Enhanced permeation, leaf retention, and plant protease inhibitor activity with bicontinuous microemulsions. Journal of Colloid and Interface Science, 383(1).

40. Song Yan, et al. Characteristics of Seepage of Microemulsions in Coal. Journal of Molecular Liquids.304(2020), doi.org/10.1016/j.molliq.2020.112742.

41. Giridhar, G., Manepalli, R. K. N. R. \& Apparao, G, 2017. Contact Angle Measurement Techniques for Nanomaterials.173-195, doi:10.1016/b978-0-323-46139-9.00008-6.

42. Li, Q., Lin, B., Zhao, S. \& Dai, H. Surface physical properties and its effects on the wetting behaviors of respirable coal mine dust. Powder Technol. 233(2013)137-145, doi:10.1016/j.powtec.2012.08.0 